\title{
Editorial
}

\section{Use of Smoking Cessation Aids: Role of Perceived Safety and Efficacy}

\author{
Stuart G. Ferguson, ${ }^{1}$ Benjamin Schüz, ${ }^{1}$ and Joe G. Gitchell ${ }^{2}$ \\ ${ }^{1}$ University of Tasmania, Australia. \\ 2 PinneyAssociates, Bethesda, MD, USA
}

Keywords: nicotine replacement, NRT, compliance, adherence, safety and efficacy

The majority of smokers indicate that they would like to quit. It has been estimated that approximately three quarters of Australian smokers have tried to change their behaviour in the last 12 months (Scollo \& Winstanley, 2008); similarly, more than half of US smokers report having tried to quit in the last year (Centers for Disease Control and Prevention [CDC], 2011). Despite their interest in quitting, the proportion of smokers who successfully quit each year is very low (CDC, 2011). While other factors are also important, poor cessation rates can partly be attributed to the low uptake of efficacious smoking cessation methods, particularly pharmacotherapies (Shiffman, Brockwell, Pillitteri, \& Gitchell, 2008).

Why might smokers who are interested in quitting avoid using cessation aids that have been demonstrated to improve their chances of doing so? A number of recent studies have suggested that smokers' beliefs about medications likely play a role in the low utilisation rates observed. Surveys conducted in a number of countries including the United States (Ferguson et al., 2011), United Kingdom (Bobak, Shiffman, Gitchell, Bery, \& Ferguson, 2010), Europe (Etter \& Perneger, 2001), and more recently, Australia (Ferguson \& Hansen, under review) - have consistently found that a sizable proportion of smokers have concerns about the safety and efficacy of nicotine replacement therapy (NRT) products. Concerns observed include safety concerns (e.g., that they are just as dangerous as cigarettes, can cause cancer, are addictive) and concerns about the effectiveness of these products as aides to cessation. Although work in this area has focused on NRT, it is likely that smokers also harbour concerns about the other smoking cessation pharmacotherapies as well.
In and of themselves, concerns about medications are not necessarily of clinical concern; in fact, it has been suggested that most people tend to hold negative views on medication in general; in particular, regarding safety issues such as side-effects and fear of dependency, and that these general beliefs have little impact on behaviour (Horne, Weinman, \& Hankins, 1999). However, specific beliefs about the necessity and concerns about one's own medication are well-evidenced predictors of medication adherence (e.g., Clifford, Barber, \& Horne, 2008). It is therefore perhaps not surprising that studies have found a link between NRT concerns and the actual use of these products: smokers with safety and efficacy concerns are less likely to have used NRT in the past, and are less likely to say that they intend to use it (or any other cessation medication for that matter) in the future. Furthermore, even when smokers with concerns do use these medications, they tend to be less compliant with dosing directions (in terms of pieces of nicotine gum per day), and are less likely to adhere to the recommended duration of treatment (Shiffman, Ferguson, Rohay, \& Gitchell, 2008), perhaps indicative of a desire to minimise exposure to the medicine. Just as failure to use in the first place obviously limits the utility of a medication, suboptimal compliance and adherence are of clinical important because these usage behaviours are associated with significantly poorer treatment outcome (Shiffman, 2007; Shiffman, Sweeney, Ferguson, Sembower, \& Gitchell, 2008).

Research in other medication classes may aid our understanding of this phenomenon - there is a wide body of research evidence suggesting that beliefs about efficacy and concerns about medications are important predictors of medication adherence (Horne \& Weinman, 1999). 
People who are convinced of the necessity, and at the same time hold little concern about their medication, are more likely use their medication as directed (e.g., Clifford, Barber, \& Horne, 2008). Importantly, it has been shown that these cognitions are amenable to change, and that change in these beliefs in turn is related to changes in adherence (Schüz et al., 2011).

If safety and efficacy concerns are directly linked to both willingness to adopt cessation medications and patterns of post-adoption use - and the data collected so far are correlational, so we do not know for certain if they are - and if such medication beliefs are amenable to change as evidence suggests they are, it would suggest that providing education to correct misperceptions may be beneficial. One study conducted by our group suggested that such education may indeed be helpful. As part of a large survey examining smokers' perceptions about smoking and medications (Ferguson et al., 2011), we selected smokers who displayed concerns about the safety of NRT and probed whether providing additional information would increase their willingness to use NRT as part of a future quit attempt. Following the provision of corrective information, more than half of the smokers expressed an increased willingness to use NRT as part of a future quit attempt. Furthermore, the smokers in this study appeared eager for information about smoking and quitting; at the end of the survey we offered smokers the opportunity for feedback on their responses to the safety and efficacy questions and $84 \%$ of the sample requested this additional information.

In order to modify misperceptions about NRT safety, it is necessary to understand whether they might serve a purpose to the individual. Such misperceptions could be cognitive biases that serve the purpose of reducing cognitive dissonance in smokers arising from a disparity between their smoking and their attitudes towards smoking. It has been shown that in order to reduce cognitive dissonance, people tend to systematically negate information that could induce cognitive dissonance (motivated reasoning, Kunda, 1990). It has also been shown that smokers are particularly prone to engaging in self-serving cognitive biases; for example, in systematically underestimating the risk of conceiving smoking-related diseases (McMaster \& Lee, 1991). Psychological theory — in particular, self-affirmation theory (Steele, 1988) — suggests that the systematic underestimation of risk and NRT safety misconceptions could be self-serving cognitive biases that prevent smokers from having to admit that they engage in unwise behaviour, despite better knowledge. Systematic safety concerns could therefore prevent smokers from having to admit that NRT might be a possible pathway to smoking cessation ('As NRT is unsafe, I can't use it and therefore don't have to stop smoking'). According to theory, such cognitions serve the purpose of reducing threat to self-perceptions of being a rational, complete person (Sherman \& Cohen, 2006). Self-affirmation theory further poses that giving individuals the possibility to affirm unrelated domains of their self-image — such as personal values - reduces the need to defensively process threatening information, thus enabling individuals to more objectively appraise information. In fact, it has been shown that self-affirmed individuals process potentially discordant information more objectively (for an overview, see Sherman \& Cohen, 2006), and research in the smoking domain suggests that self-affirming smokers are both more likely to accept smoking-related risk information (Harris, Mayle, Mabbott, \& Napper, 2007) and more likely to form intentions to stop and engage in preparatory behaviours (Armitage, Harris, Hepton, \& Napper, 2008). This suggests that examining and treating safety misperceptions as potential self-serving cognitive biases has potential in increasing the acceptance and subsequent adherence to NRT.

In summary, a number of studies have now reported that a large percentage of smokers have concerns about the safety and effectiveness of smoking cessation medications; in particular, NRT. Such concerns are of clinical interest because they appear to be related to medication use (adoption and compliance). Understanding the role of misconception and how smokers process information intended to address these misperceptions may be a promising way to counter such perceptions and increase the adoption and compliant use of smoking cessation medications.

\section{Acknowledgment}

Dr Ferguson is supported through a fellowship from Cancer Council Tasmania.

\section{Conflict of Interest}

Through their work at PinneyAssociates, SGF \& JGG provide consulting services on an exclusive basis to GlaxoSmithKline Consumer Healthcare (GSKCH), makers of nicotine replacement products for smoking cessation. However, GSKCH had no role in the current review, did not support it financially, nor review it prior to submission.

\section{References}

Armitage, C.J., Harris, P.R., Hepton, G., \& Napper, L. (2008). Self-affirmation increases acceptance of health-risk information among UK adult smokers with low socioeconomic status. Psychology of Addictive Behaviors, 22(1), 88-95. doi: 10.1037/0893-164X.22.1.88

Bobak, A., Shiffman, S., Gitchell, J.G., Bery, J., \& Ferguson, S.G. (2010). Perceived safety of nicotine and the use of nicotine replacement products among current smokers in Great Britain: Results from two national surveys. Journal of Smoking Cessation, 5(2), 115-122.

Centers for Disease Control and Prevention. (2011). MMWR weekly: Quitting smokingamongadults — United States, 20012010. Retrieved from http://www.cdc.gov/mmwr/preview/ $\mathrm{mmwrhtml} / \mathrm{mm} 6044 \mathrm{a} 2 . \mathrm{htm}$ ?s_cid=\%20mm6044a2.htm_w 
Clifford, S., Barber, N., \& Horne, R. (2008). Understanding different beliefs held by adherers, unintentional nonadherers, and intentional nonadherers: Application of the NecessityConcerns Framework. Journal of Psychosomatic Research, 64(1), 41-46. doi: 10.1016/j.jpsychores.2007.05.004

Etter, J.F., \& Perneger, T.V. (2001). Attitudes toward nicotine replacement therapy in smokers and ex-smokers in the general public. Clinical Pharmacology and Therapeutics, 69(3), 175-183.

Ferguson, S.G., \& Hansen, E.C. (Under review). A preliminary examination of cognitive factors that influence smoking during pregnancy.

Ferguson, S.G., Gitchell, J.G., Shiffman, S., Sembower, M.A., Rohay, J.M., \& Allen, J. (2011). Providing accurate safety information may increase a smoker's willingness to use nicotine replacement therapy as part of a quit attempt. Addictive Behaviours, 36, 713-716.

Harris, P.R., Mayle, K., Mabbott, L., \& Napper, L. (2007). Self-affirmation reduces smokers' defensiveness to graphic on-pack cigarette warning labels. Health Psychology, 26(4), 437-446. doi: 10.1037/0278-6133.26.4.437

Horne, R., \& Weinman, J. (1999). Patients' beliefs about prescribed medicines and their role in adherence to treatment in chronic physical illness. Journal of Psychosomatic Research, 47(6), 555-567.

Horne, R., Weinman, J., \& Hankins, M. (1999). The Beliefs About Medicines Questionnaire: The development and evaluation of a new method for assessing the cognitive representation of medication. Psychology \& Health, 14, 1-24.

Kunda, Z. (1990). The case for motivated reasoning. Psychological Bulletin, 108(3), 480-498.

McMaster, C., \& Lee, C. (1991). Cognitive dissonance in tobacco smokers. Addictive Behaviors, 16(5), 349-353. doi: 10.1016/0306-4603(91)90028-g
Schüz, B., Wurm, S., Ziegelmann, J.P., Warner, L.M., TeschRömer, C., \& Schwarzer, R. (2011). Changes in functional health, changes in medication beliefs, and medication adherence. Health Psychology, 30(1), 31-39.

Scollo, M.M., \& Winstanley, M.H. (2008). Tobacco in Australia: Facts and Issues. (3rd ed.). Melbourne, Australia: Cancer Council Victoria. Retrieved from http://www. tobaccoinaustralia.org.au

Sherman, D.K., \& Cohen, G.L. (2006). The psychology of self-defense: Self-affirmation theory. Advances in Experimental Social Psychology, 38, 183-242. doi: 10.1016/S00652601(06)38004-5

Shiffman, S. (2007). Use of more nicotine lozenges leads to better success in quitting smoking. Addiction, 102(5), 809-814.

Shiffman, S., Brockwell, S.E., Pillitteri, J.L., \& Gitchell, J.G. (2008). Use of smoking-cessation treatments in the United States. American Journal of Preventative Medicine, 34, 102111.

Shiffman, S., Sweeney, C.T., Ferguson, S.G., Sembower, M.A., \& Gitchell, J.G. (2008). Relationship between adherence to daily nicotine patch use and treatment efficacy: Secondary analysis of a 10-week randomized, doubleblind, placebo-controlled clinical trial simulating overthe-counter use in adult smokers. Clinical Therapy, 30(10), 1852-1858.

Shiffman, S., Ferguson, S.G., Rohay, J., \& Gitchell, J.G. (2008). Perceived safety and efficacy of nicotine replacement therapies among US smokers and ex-smokers: Relationship with use and compliance. Addiction, 103, 13711378.

Steele, C.M. (1988). The psychology of self-affirmation: Sustaining the integrity of the self. In L. Berkowitz (Ed.), Advances in experimental social psychology (vol. 21, pp. 261-302). San Diego, CA: Academic Press. 